\title{
A child with anorexia nervosa presenting with severe infection with cytopenia and hemophagocytosis: a case report
}

\author{
Masao Suda', Shinichiro Nagamitsu", Masahiro Kinosita', Michiko Matsuoka², Shuichi Ozono', Yasushi Otsu', \\ Yushiro Yamashita ${ }^{1}$ and Toyojiro Matsuishi ${ }^{1}$
}

\begin{abstract}
Background: Patients with anorexia nervosa in the acute phase have physical complications, such as infectious disease. Although hemophagocytic syndrome due to infection is a rare complication in anorexia nervosa, early identification for hemophagocytosis is important for avoiding a life-threatening condition.

Case presentation: We report a case of a 12-year-old girl with anorexia nervosa presenting with infection with cytopenia and hemophagocytosis during initial nutritional therapy. She developed pyrexia, abdominal pain, and diarrhea during inpatient treatment. Although intravenous antibiotics were administered, the symptoms persisted. Acinetobacter baumannii was detected in blood culture. Hemophagocytosis was present in the bone marrow. Gamma globulin therapy was effective, with improvement in symptoms and cytopenia.

Conclusions: Although our case did not fulfill the criteria of hemophagocytic syndrome, clinicians should consider severe infection in anorexia nervosa with cytopenia and hemophagocytosis.
\end{abstract}

Keywords: Anorexia nervosa, Severe infection, Hemophagocytosis, Acinetobacter baumannii

\section{Background}

Patients with anorexia nervosa (AN) in the acute phase have physical complications, such as bradycardia, hypotension, hypothermia, brain atrophy, and infectious disease. These patients also have life-threatening medical complications with arrhythmia, abnormal electrolyte metabolism, refeeding syndrome, and sepsis. AN can also occur in children, and early onset cases are increasing. Medical complications of AN in children are different from those in adults. Katzman reported that alterations in linear growth, impaired bone mineral accretion, and structural and functional brain changes are greater in children with AN [1]. The incidence of viral and bacterial infection is relatively uncommon in children and adult AN. However delayed recognition of infection because of a reduced or absent fever response, leads to a delay in the diagnosis of infection [2]. Brown et al. reported that changes in the immune system and cytokinesin AN occur in association with fewer symptomatic viral infections and a poorer response to bacterial infection [3]. This leads to delayed diagnosis and increased morbidity and mortality. Although hemophagocytic syndrome (HPS) due to infection is a rare complication in AN, early identification for hemophagocytosis is important for avoiding a life-threatening condition.

Infection associated with (HPS) is a life-threatening hyperinflammatory syndrome with primary symptoms of prolonged fever, cytopenia, and hemophagocytosis by activated macrophages [4]. Although the clinical course of HPS resembles sepsis, initiation of appropriate management for HPS leads to a good prognosis.

We report here a child with AN who presented cytopenia and hemophagocytosis due to Acinetobacter baumannii during acute management, and had successful treatment with immunoglobulin.

\footnotetext{
* Correspondence: kaoru@med.kurume-u.ac.jp

${ }^{1}$ Department of Pediatrics and Child Health, Kurume University School of

Medicine, 67 Asahi-machi Kurume City, Fukuoka 830-0011, Japan

Full list of author information is available at the end of the article
} 


\section{Case presentation}

The patient was a 12-year-old Japanese schoolgirl with weight loss. She had been healthy her entire life, and she originally had a strong sense of self-assertion and an uncompromising personality. She developed anorexia and weight loss of $20 \%$ during 2 months. She presented with a preoccupation of thinness, restriction of food intake, fearfulness of weight gain, and secondary amenorrhea. She was diagnosed as having a restricting type of AN according to the Great Ormond Street (GOS) criteria [5]. We applied the (GOS) criteria which were developed for this age. The GOS criteria are considered in younger children who rarely complain of a fear of being fat or distortion of body image. Our patient was hospitalized for treatment at our hospital and received treatment of enteral and peripheral parenteral nutrition (PPN), psychotherapy, and behavior therapy.

On admission, her height and body weight were $143.2 \mathrm{~cm}$ and $26.6 \mathrm{~kg}$, respectively. The body mass index (BMI) and BMI standard deviation score was 13 and -3.44 , respectively. The degree of obesity was $-28.2 \%$. Vital signs were almost within the normal range except for heart rate. Body temperature was $36.2{ }^{\circ} \mathrm{C}$, blood pressure was $92 / 50 \mathrm{mmHg}$, respiratory rate was 18 breaths per minute, and heart rate was 60 beats per minute). Cold extremities, poor skin turgor, and hypertrichosis were observed. The patient's blood examination at admission showed normal values except for total cholesterol (Table 1).

The first step of nutritional treatment consisted of a combination of oral food intake, enteral nutrition with a nasogastric tube, and PPN. After this nutritional and behavioral combination therapy, she gained weight and tube feeding was suspended. However, immediately after discontinuation of tube feeding (body weight of $28.2 \mathrm{~kg}$ ), she developed pyrexia $\left(39.2{ }^{\circ} \mathrm{C}\right)$, headache, abdominal pain, and diarrhea. There was no antecedent symptom of infection, such as a reduced fever response. A laboratory examination showed a high level of C-reactive protein $(10.33 \mathrm{mg} / \mathrm{dL})$. Although the antibiotic ceftriaxone sodium $2 \mathrm{~g} /$ day was administered, she still had a fever, headache, and abdominal pain.

At 2 days after onset of the infectious condition, we diagnosed our patient with disseminated intravascular coagulation (DIC) because she met the diagnostic criteria for acute DIC, which included thrombocytopenia $\left(23 \times 10^{9} / \mu \mathrm{L}\right)$, an international normalized ratio of prothrombin time of 1.26, and fibrin degradation product of $15.2 \mu \mathrm{g} / \mathrm{mL}$. The neutrophil count was $651 / \mu \mathrm{L}$. Hemophagocytosis due to macrophages was observed in a bone marrow examination (Fig. 1). Splenomegaly was not observed in our case. The fasting triglyceride level was not higher than $265 \mathrm{mg} / \mathrm{dL}$. The serum fibrinogen level was not lower than $150 \mathrm{mg} / \mathrm{dL}$. Natural killer cell activity was not determined. The serum ferritin level was
Table 1 The patient's blood examination data at admission

\begin{tabular}{|c|c|c|}
\hline & Normal value & Patient's data \\
\hline White blood cells $(/ \mu \mathrm{L})$ & $3800-10,100$ & 5000 \\
\hline Hemoglobin (g/dL) & $11.9-14.9$ & 13.4 \\
\hline Hematocrit (\%) & $35.0-43.0$ & 40.3 \\
\hline 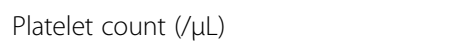 & $180-440 \times 10^{9}$ & $242 \times 10^{9}$ \\
\hline Aspartate aminotransferase $(\mathrm{U} / \mathrm{L})$ & $15-30$ & 17 \\
\hline Alanine aminotransferase (U/L) & $9-28$ & 11 \\
\hline Lactase dehydrogenase (U/L) & $145-270$ & 207 \\
\hline Alkaline phosphatase (U/L) & $300-1380$ & 255 \\
\hline Glutamyl transpeptidase (U/L) & $8-34$ & 12 \\
\hline Cholinesterase (U/L) & $235-460$ & 187 \\
\hline Total bilirubin (mg/dL) & $0.3-1.1$ & 0.68 \\
\hline Total protein (g/dL) & $6.3-7.8$ & 7.03 \\
\hline Albumin (g/dL) & $3.8-4.7$ & 4.63 \\
\hline Blood urea nitrogen (mg/dL) & $6.8-19.2$ & 19.4 \\
\hline Creatinine (mg/dL) & $0.39-0.69$ & 0.76 \\
\hline Uric acid (mg/dL) & $2.9-6.3$ & 5.45 \\
\hline Creatine kinase $(U / L)$ & $45-210$ & 58 \\
\hline Sodium (mEq/L) & $138-144$ & 136 \\
\hline Potassium (mEq/L) & $3.6-4.7$ & 5.2 \\
\hline Chlorine (mEq/L) & 102-109 & 99 \\
\hline Calcium (mg/dL) & $8.7-10.1$ & 9.83 \\
\hline Phosphorus (mg/dL) & $3.6-5.8$ & 3.92 \\
\hline Magnesium (mg/dL) & $1.8-2.2$ & 1.9 \\
\hline Copper ( $\mu g / d L)$ & $75-102.8$ & 95 \\
\hline Total cholesterol (mg/dL) & $125-230$ & 399 \\
\hline Triglyceride (mg/dL) & $41-138$ & 96 \\
\hline Free triiodothyronine $(\mathrm{pg} / \mathrm{mL})$ & $2.3-4.0$ & 0.8 \\
\hline Free thyroxine (ng/dL) & $0.9-1.7$ & 0.88 \\
\hline Thyroid-stimulating hormone $(\mu \mathrm{I} / \mathrm{mL})$ & $0.5-5.0$ & 0.605 \\
\hline
\end{tabular}

not higher than $500 \mathrm{ng} / \mathrm{mL}$. The soluble interleukin-2 receptor level was not higher than $2400 \mathrm{U} / \mathrm{mL}$. We began administration of gabexate mesilate for DIC with sepsis and changed the antibiotics to vancomycin hydrochloride and tazobactam sodium + piperacillin sodium (1:8) for the possibility of Methicillin-resistant Staphylococcus or Gram-negative bacillary infection. However, the high level of fever continued. Her hemoglobin and platelet levels declined to $10.1 \mathrm{~g} / \mathrm{dL}$ and $14 \times 10^{9} / \mu \mathrm{L}$, respectively, and platelet transfusion (10 units) was required. Because the albumin level declined to $2.65 \mathrm{~g} / \mathrm{dL}$, we then administered human serum albumin for 2 days. We detected $A$. baumannii in her blood culture. We started treatment with $\gamma$-globulin at $1 \mathrm{~g} / \mathrm{kg} / \mathrm{dose}$ for 1 day, which resulted in decreased fever and improvement of clinical symptoms, including the headache, abdominal 


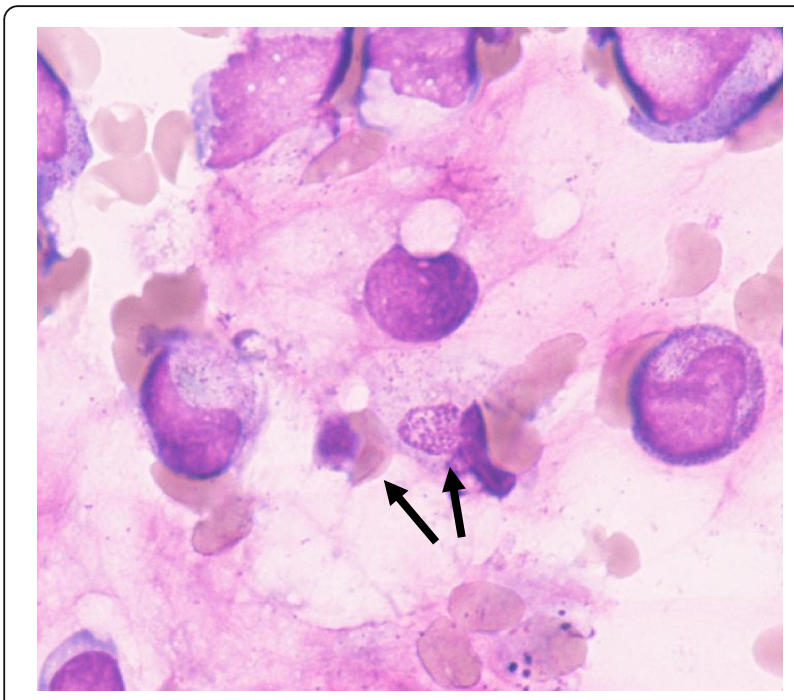

Fig. 1 May-Giemsa staining of the bone marrow. A macrophage phagocytizing a red blood cell and granulocyte can be seen (arrows)

pain, and diarrhea. At 4 days after administration of $\gamma$-globulin, her platelets rose to $181 \times 10^{9} / \mu \mathrm{L}$.

\section{Discussion}

Severe infection is a common complication of AN and can cause a fatal condition [6]. Our patient developed severe infection during a short disease duration. Physicians need to be aware of infection at any time of the acute and recovery phase of AN.

Immunosuppression due to malnutrition in AN is a possible cause of serious and prolonged infection. A reduced or absent fever response in AN may lead to a delay in diagnosis of infection. Hypoalbuminemia due to malnutrition may reduce the efficacy of antibiotic therapy, resulting in a prolonged febrile condition. Our patient presented with a prolonged fever response with antibiotic resistance, and she developed a severe condition that required blood transfusion.

Our case fulfilled only three (fever $>38.5{ }^{\circ} \mathrm{C}$, cytopenia, and hemophagocytosis) of eight criteria for hemophagocytic lymphohistiocytosis (HLH) [4]. Hypertriglyceridemia, hypofibrinogenemia, natural killer cell activity, and splenomegaly were not observed in our case. Our patient's serum fibrinogen and ferritin levels were not high. Although, we could not diagnose our patient as having HLH, she might have developed HLH if we did not provide early intervention. She did not have a family history of HLH. In our case, the state of infectious hemophagocytosis was likely caused by $A$. baumannii.

Acinetobacter was identified from the patient's blood culture as a cause of serious infection with phagocytosis. A. baumannii is commonly isolated from the hospital environment, and preferentially colonizes aquatic environments such as the respiratory tract in intubated patients. A. baumannii causes bacteremic complications in patients with an indwelling central venous catheter [7]. In our case, although the route of Acinetobacter infection was not identified, PPN or enteral feeding might have been the cause of the bacterial contamination $[8,9]$.

Alternatively, bacterial translocation might be a route of infection. Intestinal mucosal atrophy with long-term starvation in AN might increase the risk of bacterial translocation [10]. There are also recent reports of multidrug-resistant Acinetobacter infection in hospitals [11]. Therefore, care should be taken to reduce the risk for Acinetobacter infections as nosocomial infections in patients with AN with PPN or enteral tubes.

\section{Conclusions}

In summary, we report a childhood case of AN where the patient presented with infection with cytopenia and hemophagocytosis during initial nutritional therapy. Regardless of HPS, clinicians should consider severe infection in AN with cytopenia and hemophagocytosis.

\section{Abbreviations}

AN: Anorexia nervosa; BMI: Body mass index; DIC: Disseminated intravascular coagulation; HLH: Hemophagocytic lymphohistiocytosis; HPS: Hemophagocytic syndrome; PPN: Peripheral parenteral nutrition

\section{Acknowledgements}

We thank Ellen Knapp, PhD, from Edanz Group (www.edanzediting.com/ac) for editing a draft of this manuscript.

\section{Funding}

This work was supported by grants from the Ministry of Health, Labour and Welfare (\#29040501).

Availability of data and materials

Al data of this case report are available in this manuscript.

\section{Authors' contributions}

All authors were involved in the management of the patient and the preparation of the case report. All authors read and approved the final manuscript.

Ethics approval and consent to participate

Not applicable.

\section{Consent for publication}

The patient provided written informed consent for publication.

\section{Competing interests}

The authors declare that they have no competing interests.

\section{Publisher's Note}

Springer Nature remains neutral with regard to jurisdictional claims in published maps and institutional affiliations.

\section{Author details}

'Department of Pediatrics and Child Health, Kurume University School of Medicine, 67 Asahi-machi Kurume City, Fukuoka 830-0011, Japan.

${ }^{2}$ Department of Psychiatry, Kurume University School of Medicine, Kurume, Japan. 
Received: 12 April 2017 Accepted: 26 July 2017

\section{Published online: 05 September 2017}

\section{References}

1. Katzman DK. Medical complications in adolescents with anorexia nervosa: a review of the literature. Int J Eat Disord. 2005;37:52-9.

2. Brown RF, Bartrop R, Beumont P, Birmingham CL. Bacterial infections in anorexia nervosa: delayed recognition increases complications. Int J Eat Disord. 2005;37:261-5.

3. Brown RF, Bartrop R, Birmingham CL. Immunological disturbance and infectious disease in anorexia nervosa: a review. Acta Neuropsychiatr. 2008;20:117-28.

4. Henter J, Horne A, Aricó M, Egeler RM, Filipovich AH, Imashuku S, et al. $\mathrm{HLH}-2004$ : Diagnostic and therapeutic guidelines for hemophagocytic. Pediatr Blood Cancer. 2007:48:124-31.

5. Nicholls D, Chater R, Lask B. Children into DSM don't go: a comparison of classification systems for eating disorders in childhood and early adolescence. Int J Eat Disord. 2000;28:317-24.

6. Haruta I, Asakawa A, Ogiso K, Amitani H, Amitani M, Tsai M, et al. A case of anorexia nervosa with disseminated intravascular coagulation syndrome. Int J Eat Disord. 2012;45:453-5.

7. Munoz-Price LS, Weinstein RA. Acinetobacter infection. N Engl J Med. 2008; 358:1271-81. doi:10.1056/NEJMra070741

8. Kaul R, Burt JA, Cork L, Dedier H, Garcia M, Kennedy C, et al. Investigation of a multiyear multiple critical care unit outbreak due to relatively drugsensitive Acinetobacter baumannii: risk factors and attributable mortality. J Infect Dis. 1996;174:1279-87.

9. Chopra T, Marchaim D, Johnson PC, Awali RA, Doshi H, Chalana I, et al. Risk factors and outcomes for patients with bloodstream infection due to Acinetobacter baumannii-calcoaceticus complex. Antimicrob Agents Chemother. 2014;58:4630-5. doi:10.1128/AAC.02441-14.

10. Song J, Wolf SE, Wu XW, Finnerty CC, Gauglitz GG, Herndon DN, et al. Starvation-induced proximal gut mucosal atrophy diminished with aging. JPEN J Parenter Enteral Nutr. 2009;33:411-6.

11. Roy S, Viswanathan R, Singh A, Das P, Basu S. Gut colonization by multidrug resistant and carbapenem-resistant Acinetobacter baumanni in neonates. Eur J Clin Microbiol Infect Dis. 2010;29:1495-500. doi:10. 1007/s10096-010-1030-z

\section{Submit your next manuscript to BioMed Central and we will help you at every step:}

- We accept pre-submission inquiries

- Our selector tool helps you to find the most relevant journal

- We provide round the clock customer support

- Convenient online submission

- Thorough peer review

- Inclusion in PubMed and all major indexing services

- Maximum visibility for your research

Submit your manuscript at www.biomedcentral.com/submit 